\begin{tabular}{|c|c|c|}
\hline Beitr. Ent. & Keltern & ISSN 0005-805X \\
\hline $\mathbf{5 5}(2005) 2$ & S. $305-312$ & 27.12 .2005 \\
\hline
\end{tabular}

\title{
A remarkable new genus Manzumbadoa gen. n. from Costa Rica
}

\section{(Diptera: Sciaridae)}

With 8 figures

Mathias Jaschhof and Werner Mohrig

\section{Zusammenfassung}

Die Sciaride Manzumbadoa bradysioides gen. et sp. n. aus Costa Rica wird beschrieben. Das Flügelgeäder von Manzumbadoa zeichnet sich durch eine Merkmalskombination aus, die nicht nur innerhalb der Sciaridae, sondern innerhalb der gesamten Sciaroidea einmalig ist und mehrere Apomorphien einschließt. Besonders bemerkenswert ist das Auftreten der fusionierten Radio-Media (frm), ein für die Sciaridae bisher unbekanntes Merkmal. Manzumbadoa gehört in einen Verwandtschaftskomplex um die Gattung Bradysia Winnertz, dessen Phylogenie bisher nur ansatzweise verstanden wird.

\section{Summary}

The sciarid Manzumbadoa bradysioides gen. et sp. $\mathrm{n}$. from Costa Rica is described. This new genus is outstanding for its wing venation that is unique not only among the Sciaridae but all the Sciaroidea. In particular, the presence of the fused radio-media (frm) in Manzumbadoa bradysioides is most remarkable as no other species of the Sciaridae shows this character. Manzumbadoa belongs to a group of genera around Bradysia WINNERTZ, the phylogeny of which is still poorly understood.

\section{Stichwörter}

Diptera, Sciaroidea, Sciaridae, neue Gattung, neue Art, Costa Rica

\section{Keywords}

Diptera, Sciaroidea, Sciaridae, new genus, new species, Costa Rica

\section{Introduction}

Among the almost 2000 described species of the Sciaridae (Menzel 1999) variation in the wing vein pattern is very small. The characteristic, uniform wing venation is perhaps the best indicator that a particular sciaroid does belong to the family Sciaridae. The venation as typical for the Sciaridae is, compared with the ground plan of the Bibionomorpha, widely reduced (for instance, Menzel \& Mohrig 2000: Figs 73-78) and includes the costalization of the anterior veins, i.e. the first and fifth radial branches (R1 and R5, respectively) run close and usually parallel to the costa (C), with an extremely short, almost vertical radial sector (Rs) in between. Further, the bifurcated media, consisting of a common stem and the branches M1 and M2, branches off from the basal transverse 
vein (tb) before the level of Rs. Apart from this anterior fork, a posterior fork is made from the two branches of the anterior cubitus ( $\mathrm{CuA} 1$ and $\mathrm{CuA} 2$, respectively) which usually have a common stem. There is little deviation from this general pattern. On the one hand, atavistic aberrations occur that are very rare, but apparently accumulate within the genera Bradysia Winnertz and Scatopsciara Edwards (Menzel \& Mohrig 2000: Figs 79a-e). On the other hand, striking species- and genus-specific deviations include the strongly curved M1 and absence of the CuA-stem (Menzel \& Mohrig 2000: Figs 74 and 78, respectively). In some species of the Neotropical genus Zygomma ENDERLEIN (for instance, Zygomma transversalis Edwards, 1954), the strongly curved M1 may even be accompanied by an additional cross-vein that interconnects M1 and R5.

In the course of recent studies by one of us (M. J.) of various groups of Sciaroidea in Costa Rica, another sciarid with an unusual vein pattern was found and is here described as Manzumbadoa bradysioides gen. et sp. $\mathrm{n}$. Wing venation in this species is very remarkable as it does not follow the basic pattern of Sciaridae in a particular detail that is relevant for phylogenetic considerations on a family-group level within the Sciaroidea. As is found in Ditomyiidae, Keroplatidae and Rangomaramidae, wing venation in Manzumbadoa includes the presence of a fused radio-media (frm), with $M 1+2$ branching off from R5 beyond the level of Rs. Due to this peculiar vein pattern, identification as a sciarid of Manzumbadoa bradysioides may fail when other characters, or character combinations are not taken into consideration.

\section{Material and methods}

Specimens of the new species were picked from unsorted Malaise trap samples in the care of the Instituto Nacional de Biodiversidad (INBio), Santo Domingo, Costa Rica. Only eight specimens were found among material from some 110 samples, containing many thousands of sciarids, from various regions within this small, naturally diverse country. Type specimens were dehydrated in ethanol, treated with beechwood creosote and mounted on microscopic slides in Canada balsam; another specimen is kept in ethanol. The holotype and four paratypes are deposited in the INBio collection, two paratypes in the Mohrig collection, Puddemin, Germany. Usage of morphological terminology follows that of Söli (1997) for Mycetophilidae and Jaschнof \& Didham (2002) for some terms regarding male terminalia. Drawings were made using an Olympus BX50 microscope in combination with the U-DA drawing unit.

\section{Genus Manzumbadoa gen. n.}

Type species: Manzumbadoa bradysioides sp. n., described below.

Description: Pubescence, where present, strikingly long.

Head: Head capsule higher than long; setation short and undifferentiated. Postfrons slightly two-lobed, setose, with slightly two-pointed frontal tubercle. Face large, setose. Clypeus narrower than, and clearly separated from face, setose. In males, antennae longer than abdomen; in females, antennae shorter than abdomen. Scape and pedicel subglobular, setose, dark. Flagellum dark, lighter towards apex; with 14 flagellomeres, first 
flagellomere longest, terminal flagellomere longer than penultimate; each flagellomere cylindrical, little more than twice as long as wide, with rather short neck clearly demarcated from and lighter than node. Flagellum without microtrichia. Each flagellomere densely covered with setae arising from membranous rings, setae as long as diameter of flagellomere or shorter. Ocelli present. Eyes reniform, at vertex with very narrow but complete bridge; with numerous fine interommatidal setulae. Mouthparts well developed, with slightly prolonged proboscis. Labrum beak-like, subtriangular, well sclerotized, non-setose. Lingua with dense fringes apically. Maxillae with lacinia absent. Maxillary palpus long, with 4 palpomeres; first palpomere ('presegment') small, smooth and bare. Palpomeres 2-4 setose, with some setae spine-like; palpomere 2 with numerous short hyaline sensory hairs; palpomere 2 thickest and 4 clearly longest. Labial palpus strongly developed, 2-segmented; labellum 1 smaller than 2; labellum 1 non-setose; labellum 2 with numerous, partly spine-like setae.

Thorax: Setation, where present, short and fine; pubescence strikingly long. Postpronotum bare. Antepronotum finely setose. Episternum 1 setose. Epimeron 1 subtriangular, largely merged with episternum 1 . Scutum in profile slightly arched, with anterior parapsidal suture weak and median transverse suture not traceable, with even cover of setae. Scutellum clearly demarcated from scutum, with numerous setae of various lengths. Mediotergite in profile arched to slight degree, sparsely setose. Postphragma well developed, i.e. extending into abdominal cavity for half length of abdominal segment 1 . Mediotergite and laterotergites with distinct suture in between. Laterotergite large, dropshaped, little pronounced. Anepisternum subrectangular; separated from preepisternum 2 by distinct suture, setose posteriorly. Anepisternal cleft distinct. Preepisternum 2 much larger than anepisternum, subtriangular ventrally, with few setae in upper half or near anapleural suture. Mid-pleural pit pronounced. Epimeron 2 with deep cleft dorsally indicating a subdivision into upper anepimeron and lower katepimeron, latter strongly narrowed ventrally and extending to upper rim of episternum 3. Episternum 3 longitudinally divided by membranous cleft, with upper portion smaller than lower portion, with some short setae on both portions. Epimeron 3 very narrow. Openings of spiracles without striking features. Legs: Short and strong compared with other sciarids, like Bradysia and Zygomma. On coxae and femora, setation comparatively long and sparse. On tibiae and tarsi, setation short, very dense and including spine-like setae, latter absent on fore tibia. Tibial spurs 1:2:2; on mid and hind tibiae, one spur slightly shorter than other. Fore tibia with barely delineated anteroapical depression bearing setae, large trichia and distal comb of stiff setae; comb extraordinary wide and straight in one line. Pretarsal claws slightly curved, without teeth. Empodia well developed. Wing: Two times as long as wide, shorter than body. Membrane transparent, with brownish tinge, densely covered with microtrichia. Venation: $\mathrm{C}$ extending to apex of wing, ending half way between apices of R5 and M1; Sc short, ending free before level of Rs; Rs comparatively long, somewhat oblique, crossing point with R1 situated more distally than that with transverse vein; ta absent due to presence of frm; tb twice as long as frm; $\mathrm{R} 1$ long, joining $\mathrm{C}$ clearly beyond midpoint of wing; R5 long, extending closely to apex of wing; M-stem branching off beyond level of Rs resulting in presence of frm, clearly shorter than M-fork; Mfork diverging in distal half; $\mathrm{CuA} 1$ and $\mathrm{CuA} 2$ with very short common stem; $\mathrm{CuA} 2$ very pale basally and sharply bent distally; $\mathrm{CuP}$ extending beyond half length of $\mathrm{CuA} 2 ; \mathrm{A} 1$ subequal in length to $\mathrm{CuP}$ or shorter; $\mathrm{A} 2$ absent. With setae present along $\mathrm{C}$ and dorsally 
on R, R1 (also ventrally), tb, frm, and R5 (also ventrally). Halter with stem and knob subequal in length, with fine setae (few on stem and numerous on knob).

Abdomen: Sclerites densely covered with long setae. Male terminalia: Sternite 9 largely merged with bases of gonocoxites, traceable as triangular weak sclerite. Gonocoxites with deep V-shaped emargination, interconnected ventrobasally by non-setose portion including sternite 9; gonocoxal apodemes interconnected by weakly sclerotized transverse bridge. Gonostyli elongate, one-lobed, with spines terminally. Aedeagus with long, well sclerotized apodeme. Aedeagal teeth present. Tegmen wider than long, broadly rounded distally, with long ventral apodemes. Dorsal parameral apodemes long. Tergite 9 platelike, setose, longer than wide, poorly sclerotized distally. Tergite 10 present as short, bare sclerite. Cerci present as large, rounded, setose lobes. Hypoproct two-lobed, setose. Female terminalia: Corresponding with basic outline in Sciaridae.

Diagnosis and discussion:The genus Manzumbadoa is based on the following apomorphous characters that are unique among Bradysia-like sciarids (see below): (1) the presence of the frm; (2) the very long R1 that joins $\mathrm{C}$ beyond the midpoint of wing; (3) the long, oblique Rs the presence of which runs counter to the costalization of the anterior veins; and (4) the very short M-stem. Character 1 is unique among all species known of the Sciaridae. As regards character 3, the oblique inclination in Manzumbadoa differs from all other known sciarids because the crossing point of $\mathrm{Rs}$ and $\mathrm{R}+\mathrm{R} 5$ lies beyond the crossing point of $\mathrm{Rs}$ and $\mathrm{tb}$, or $\mathrm{tb}+\mathrm{ta}$, respectively. The opposite is true for other sciarids with long, oblique Rs (see, for instance, Menzel \& Mohrig 2000: Fig. 78). One might argue that these four vein characters are not independent from one another. For instance, the short M-stem might be the consequence of the presence of the frm; however, it would be hard to prove such correlations.

The genus Manzumbadoa belongs to a group of genera around Bradysia WinnerTz, 1867 sensu Toumikoski (1960). Sciarids belonging here share common characters, like the presence of the anteroapical comb of setae on the fore tibia; and male terminalia typically with comparatively simple gonostyli and simple, broadly rounded tegmen. The cosmopolitan genus Bradysia is extremely rich in species and of extraordinary complexity. In the Palearctic region, 16 species groups are recognized (Menzel \& MoHrig 2000), while the documentation of the largely undescribed diversity of Bradysia-like sciarids outside the Palearctic has just begun (Mohrig 2003; Mohrig et al. 2004). Menzel and Mohrig (2000) confess that there is no recognizable autapomorphy of Bradysia. In present understanding, characteristic for the great majority of Bradysia species is the foretibial comb of setae that is straight and moderately wide, i.e. approximately half as wide as the foretibia apically. Nevertheless, the monophyly of Bradysia, in its current delimitation, is still to be shown. Among the genera close to Bradysia is the Neotropical genus Zygomma ENDERLEIN, 1911; however, the relationship between Zygomma and Bradysia, or Zygomma and parts of Bradysia, remains unresolved (MoHrIG 2003). A broader study of Zygomma is under way (MoHrig, in prep.), but it appears already that Zygomma and Manzumbadoa share apomorphous similarities, like the tibial anteroapical depression with a very wide comb of setae distally; the mesonotum with very long, dense pubescence and very short, sparse setation; and the scutum flat. Since too little data on non-Palearctic bradysioids is published and the type-species of several genera are not yet re-studied by using modern methodology, we explicitely desist from postulating 
a sister-group relationship between Manzumbadoa and Zygomma. Solving the 'Bradysia problem' will be a very complex issue that can only be slightly touched here. How far this issue goes is indicated by the fact that several Central American species of Sciaridae cannot be assigned convincingly to either Bradysia or, alternatively, Scatopsciara Edwards, 1927 s. str. It is quite obvious that genus concepts based on Palearctic species (MeNzEL \& Mohrig 2000) must be re-considered as soon as non-Palearctic species are involved.

Considering the unusual wing venation in Manzumbadoa, dipterists less familiar with the Sciaroidea might question that this genus must be assigned to the family Sciaridae. Adult morphology does not provide an individual feature that is characteristic of this family, i.e. there is no autapomorphy recognizable for the Sciaridae (Jaschнof \& Didham 2002). Correct family assignment of Manzumbadoa needs the consideration of a character combination which includes the presence of an ocular bridge; the presence of tibial spurs; the wide insertion of the abdomen on the thorax; the large postphragma, projecting strongly into the abdomen; the four-segmented maxillary palpi (with the first segment small and smooth and often overlooked or not described); and the comparatively simple male terminalia. Even though deviating from the diagnostic pattern in the Sciaridae, wing venation in Manzumbadoa is reduced as in other sciarids (see the abbreviated Sc and anal vein (A); almost horizontal basal transversal vein (tb); and absence of the R4), a fact that gives an important hint for excluding families, like the Ditomyiidae and Keroplatidae. Among all sciaroids known to date, wing venation in Manzumbadoa is unique in that the presence of the frm is associated with the presence of the furcate $\mathrm{CuA}$ and abbreviated A1.

Etymology. This new genus is named after Manuel Zumbado of the Instituto Nacional de Biodiversidad (INBio), Santo Domingo de Heredia, Costa Rica. Herewith we honour an outstanding fighter for the cause of biodiversity research and protection, as well as a keen and knowledgable naturalist and dipterist.

\section{Manzumbadoa bradysioides sp. $\mathrm{n}$.}

(Figs 1-8)

Description (for characters not mentioned here, see genus description above)

Male. Body length: 2.9-3.1 mm. Head: Antenna with fourth flagellomere 2.2 times as long as wide (Fig. 1). Maxillary palpus as in Fig. 5.

Legs: Fore tibia with anteroapical depression bearing distal comb of some 20 setae (Fig. 2). Wing: See Fig. 3.

Terminalia: Gonocoxites (Fig. 6) with setae of various lengths; with megaseta each ventro- and dorso-distally. Gonostyli (Figs 6,7) elongate, in distal half tapering to tip, inside and distally with very short setae and long setae elsewhere, with 1 short, thick spine outside subterminally and 3 spines in line apically. Ejaculatory apodeme (Fig. 8) as long as tegmen. Tegmen (Fig. 8) with long, sclerotized ventral apodemes, membranous elsewhere and wrinkled laterally. Tergite 9 (Fig. 4) with setae of various lengths, in distal third very weak and lacking setae and trichia. Tergite 10 (Fig. 4) extending distolaterally beyond tergite 9. Cerci (Figs 4,8) large, setose, rounded terminally. Hypoproct (Fig. 8) weak, two-lobed, with 2 setae each.

Female. For characters not mentioned here, see the above description of the male. 

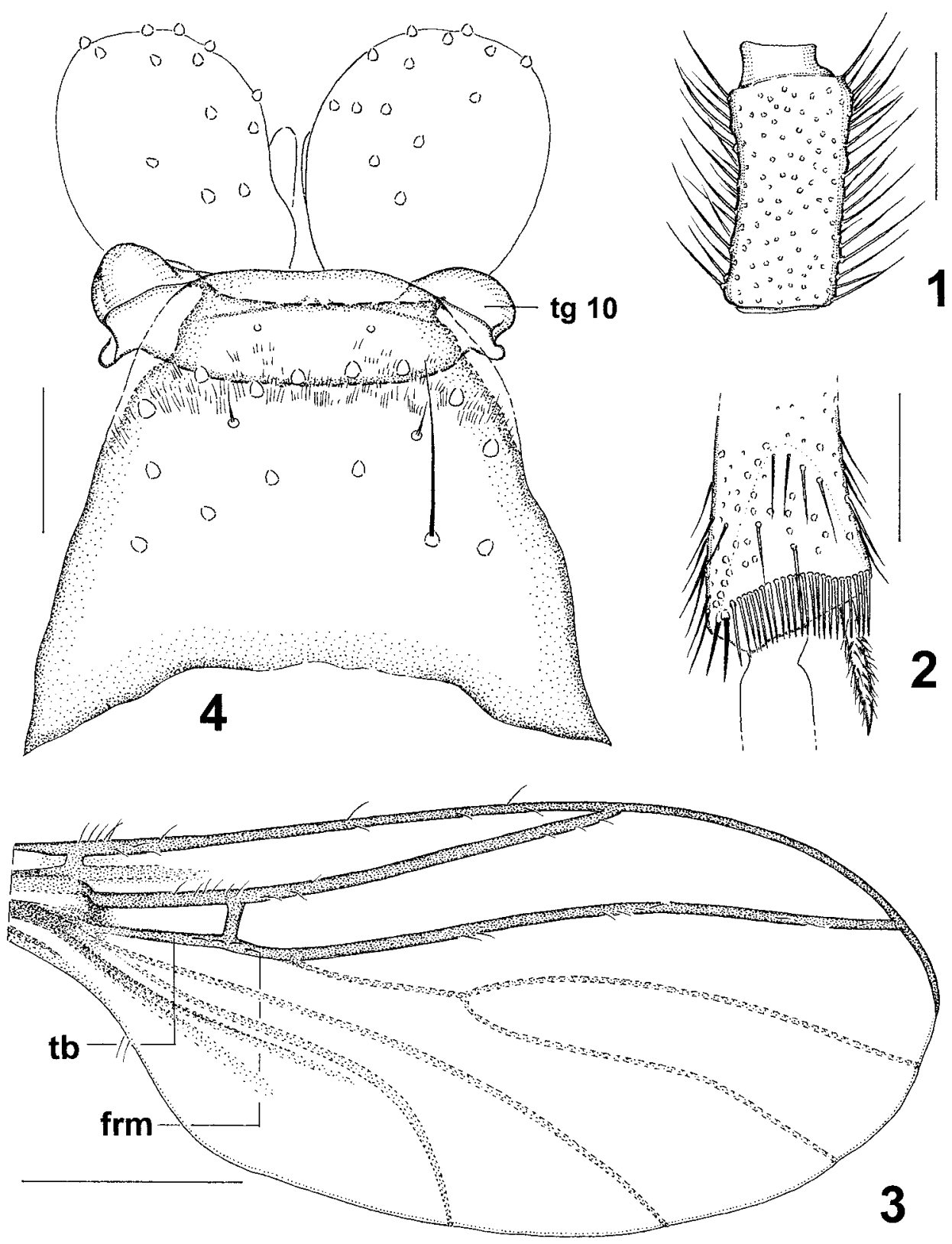

Figs 1-4: Manzumbadoa bradysioides sp. n., male. - 1: fourth antennal flagellomere, lateral view $(0.1 \mathrm{~mm})$; - 2: fore tibial anteroapical depression $(0.1 \mathrm{~mm})$; - 3: wing $(0.5 \mathrm{~mm})$; - 4: terminalia, tergites 9 and 10, dorsal view $(0.05 \mathrm{~mm}) .1$ and 2: holotype; 3 and 4: paratypes. Abbreviations in Fig. 3: tb = basal transversal vein; frm $=$ fused radio-media. In parentheses: length of scale bar. 


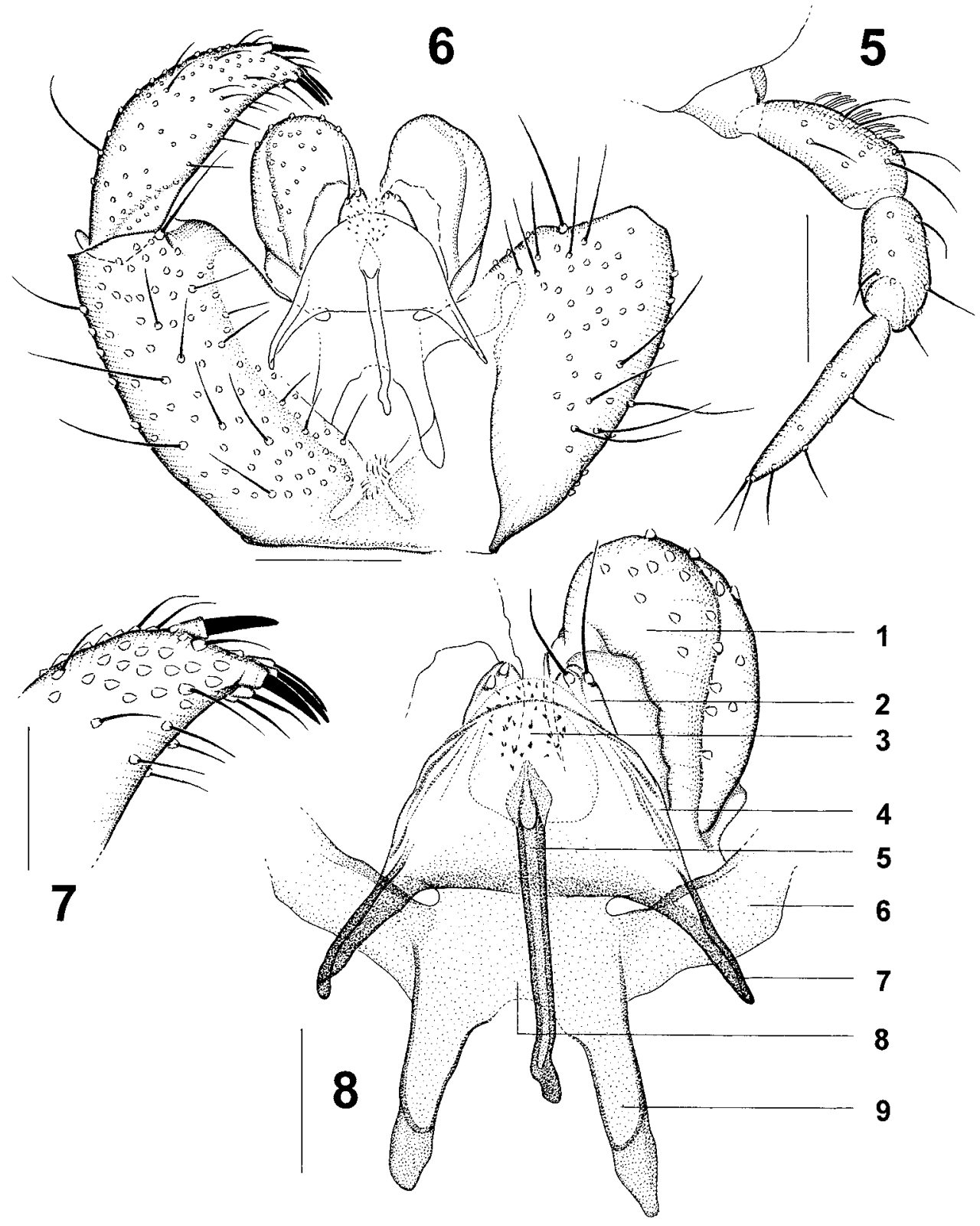

Figs 5-8: Manzumbadoa bradysioides sp. n., holotype male. - 5: maxillary palpus, lateral view $(0.1 \mathrm{~mm})$; - 6: terminalia, left side: ventral view, right side: dorsal view, right gonostylus and tergite 9 omitted $(0.1 \mathrm{~mm})$; - 7: apex of gonostylus, lateral view $(0.05 \mathrm{~mm})$; - 8: ejaculatory apodeme, tegmen and associated structures, ventral view $(0.05 \mathrm{~mm})$. Numbers referring to structural elements as follows: $1=$ cercus; 2 = hypoproct; 3 = aedeagal teeth; $4=$ tegmen; $5=$ ejaculatory apodeme; $6=$ gonocoxal apodeme; $7=$ ventral parameral apodeme; $8=$ transverse bridge; $9=$ dorsal parameral apodeme. In parentheses: length of scale bar. 
Body length: $3.0 \mathrm{~mm}$.

Abdomen: Segments 1-6 much broader than following segments. Terminalia: Without striking features that deviate from those in other sciarids.

Etymology. The species epithet 'bradysioides' indicates the similarity between the new species and typical species of the genus Bradysia, a fact that is most strikingly expressed in the outline of male terminalia.

Types. Holotype: Male, Costa Rica, Puntarenas province, Corcovado National Park, Cerro Rincón, La Tigrilla, $600 \mathrm{~m}$ above sea level, 7 Feb.-23 April 2002, by Malaise trap, J. Azofeifa (sample no. INBio 70848). Paratypes: 1 male, same data as the holotype; 2 males, 1 female, Corcovado National Park, Cerro Mueller, $744 \mathrm{~m}$ above sea level, 20 Dec. 2001-7 Feb. 2002, by Malaise trap, J. Azofeifa (no. 67160); 2 males, same locality as the holotype, but 20 Dec. 2001-7 Feb. 2002 (no. 67158).

Other material studied. 1 male (in ethanol), Corcovado National Park, $800 \mathrm{~m}$ S Cerro Rincón, 745 m above sea level, 20 Dec. 2001-7 Feb. 2002, by Malaise trap, J. Azofeifa (no. 67159).

\section{Acknowledgements}

Study of the insect collections at INBio was made possible for one of us (M. J.) through the generosity of INBio providing support both in the laboratory and in the field during a three-months visit from September to November, 2003. Catrin Jaschrof, Stockholm, Schweden, greatly assisted in the field and in sorting through numerous insect samples. Dr Frank Menzel, Deutsches Entomologisches Institut, Müncheberg, Germany, commented on the systematic position of the taxa in question and read the manuscript. Language of the manuscript was kindly improved by Mrs Birgit Sievert, Berlin, Germany.

\section{Literature}

Jaschiof, M. \& Didham, R. K. 2002: Rangomaramidae fam. nov. from New Zealand and implications for the phylogeny of the Sciaroidea (Diptera: Bibionomorpha). - Studia dipterologica Supplement, Halle (S.) 11:1-60.

Menzel, F. 1999: Familie Sciaridae. Pp. 75-80. - In: Schumann, H.; Bährmann, R. \& Stark, A.: Checkliste der Dipteren Deutschlands. - Studia dipterologica Supplement, Halle (S.) 2: 1-354.

Menzel, F. \& Mohrig, W. 2000: Revision der paläarktischen Trauermücken (Diptera: Sciaridae). - Studia dipterologica Supplement, Halle (S.) 6 (1999): 1-761.

Mohrig, W. 2003: Black fungus gnats of Central America. Part I. (Diptera, Sciaridae). - Beiträge zur Entomologie, Keltern 53 (1): 1-69.

Mohrig, W.; Röschmann, F. \& Rulik, B. 2004: The fauna of sciarid flies of the Dominican Republic (Diptera, Sciaridae). - Beiträge zur Entomologie, Keltern 54 (2): 267-331.

Tuомікоsкi, R. 1960: Zur Kenntnis der Sciariden (Dipt.) Finnlands. - Ann. Zool. Soc. Vanamo, Helsinki $21(4): 1-164$.

\section{Authors' address:}

Dr. Mathias JaschHoF

Swedish Museum of Natural History

Box 50007

S-10405 Stockholm, Sweden

Mathias.Jaschhof@nrm.se
Prof. Dr. sc. nat. Werner Mohrig

Puddemin 6

D-18574 Poseritz/Rügen

Germany 